\title{
PATRIMÔNIO E ENSINO DE HISTÓRIA: CINCO DECISÕES DO PROFESSOR
}

\author{
Margarida Maria Dias de Oliveira \\ Itamar Freitas $^{2}$
}

\begin{abstract}
Resumo: Neste artigo, problematizamos as preocupações de peritos e professores de História em torno dos objetos designados "patrimônio" e, mediante investigação bibliográfica, apresentamos teses da literatura especializada sobre cinco temas comuns em atividades de planejamento dos professores da escolarização básica: patrimônio e identidade; patrimônios nacionais e patrimônios da humanidade; virtualidade e fisicalidade do patrimônio; preservação e criação de memórias no interior das escolas; capacidades gerais ou capacidades disciplinares. Nosso objetivo imediato é apresentar cinco grupos de questões que podem servir como orientador do planejamento ou instrumento de avaliação de planos ou de ações que envolvem patrimônio e ensino de História.
\end{abstract}

Palavras-chave: Patrimônio. Planejamento. Ensino de História.

\section{HERITAGE AND HISTORY TEACHING: FIVE TEACHER DECISIONS}

Abstract: In this article, concerns of history experts and teachers around the objects called "heritage" are discussed and, through bibliographic investigation, the specialized literature is featured on five common themes in activities of planning by basic school teachers: heritage and identity; national heritage and human heritage; virtuality and physicality of heritage; preservation and creation of memories within schools; general capacities or disciplinary capacities. Our immediate objective is to present five groups of questions that can serve as a guide for planning or as an instrument for evaluating plans or actions involving heritage and History teaching.

Keywords: Heritage. Planning. History teaching.

\section{PATRIMOINE ET ENSEIGNAMENT DE L'HISTOIRE: CINQ DÉCISIONS DES ENSEIGNANTS}

Résumé: Dans cet article, nous problématisons les préoccupations des experts en histoire et des enseignants autour des objets dits «patrimoine» et, à travers une recherche bibliographique, nous présentons des thèses de la littérature spécialisée sur cinq thèmes communs dans la planification des activités des enseignants du primaire: patrimoine et identité; patrimoine

\footnotetext{
${ }^{1}$ Possui graduação em História pela Universidade Federal da Paraíba (1988), mestrado em Sociologia pela Universidade Federal da Paraíba (1994) e doutorado em História pela Universidade Federal de Pernambuco (2003). Tem experiência na área de História, com ênfase em Teoria da História e Metodologia do Ensino de História, atuando principalmente nos seguintes temas: ensino de história, livros didáticos de História, formação de professores, historiografia, memória e patrimônio cultural (histórico). Atualmente é professora Titular do Departamento de História da Universidade Federal do Rio Grande do Norte (UFRN).

${ }^{2}$ Possui licenciatura em História pela Universidade Federal de Sergipe (UFS-1996), especialização em Organização de Arquivos pela Universidade de São Paulo (USP-1997), mestrado em História Social pela Universidade Federal do Rio de Janeiro-UFRJ (2000), doutorado em Educação pela Pontifícia Universidade Católica de São Paulo (PUC/SP-2006), doutorado em História pela Universidade Federal do Rio Grande do Sul (UFRGS-2019) e pós-doutorado no Programa de Pós-Graduação em História da Universidade de Brasília (PPGH/UnB-2014). É professor do Departamento de Educação e do Mestrado Profissional em História (UFS). Tem experiência nas áreas de Ensino de História, Teoria e Metodologia da História e foi parecerista do Programa Nacional do Livro Didático (PNLD) em sete edições e da primeira versão da Base Nacional Curricular Comum (PNLD).
} 
national et patrimoine de l'humanité; virtualité et physicalité du patrimoine; préservation et création de souvenirs au sein des écoles; compétences générales ou compétences disciplinaires. Notre objectif immédiat est de présenter cinq groupes de questions pouvant servir de guide pour la planification ou d'instrument d'évaluation des plans ou des actions concernant le patrimoine et l'enseignement de l'histoire.

Mots-clés: Patrimoine; Planification; Enseignement de l'histoire.

\section{ENSEÑANZA DEL PATRIMONIO Y LA HISTORIA: CINCO DECISIONES DEL PROFESOR}

Resumen: En este artículo, problematizamos las inquietudes de expertos en historia y maestros en torno a los objetos llamados "patrimonio" y, a través de la investigación bibliográfica, presentamos tesis de la literatura especializada sobre cinco temas comunes en la planificación de actividades de maestros de escuelas básicas: patrimonio e identidad; patrimonio nacional y patrimonio de la humanidad; virtualidad y fisicalidad del patrimonio; preservación y creación de recuerdos dentro de las escuelas; habilidades generales o habilidades disciplinarias. Nuestro objetivo inmediato es presentar cinco grupos de preguntas que pueden servir como guía para la planificación o como un instrumento para evaluar planes o acciones que involucren el patrimonio y la enseñanza de la Historia.

Palabras Clave: Patrimonio. Planificación. Enseñanza de historia.

\section{Introdução}

A literatura de divulgação que relaciona patrimônio histórico e ensino de História, não raramente, acantona-se em dois polos preferenciais: categorização de patrimônio em termos do seu campo semântico e instrumentalização de práticas do professor para o patrimônio como objeto de aprendizagem (HORTA, 1999; RAMOS, 2004; BITTENCOURT, 2004; PELEGRINI, 2011; PACHECO, 2018; ZARBATO, 2018). Dizendo de outro modo, estudos do gênero focam nas histórias do pensamento e da prática de preservação ou na oferta de métodos para a educação patrimonial, estudo do meio e estratégias similares. Essa dicotomia é positiva para grupos de pesquisa especializada, não raro produzida em programas de Pós-Graduação. Na vida prática do professor de História, a dicotomia estimula uma perversa separação entre os eruditos não predispostos a aplicar o que teorizam e dos aplicadores não predispostos - e, na maioria das vezes, sem tempo - a ensaiar voos de erudição para fundamentar os seus trabalhos. Ainda para o ensino escolar, essa dicotomia estimula os professores a buscarem os melhores "métodos" de ensinar "o" patrimônio que, ao longo do artigo ficará clara, não é a atitude mais adequada.

Neste artigo, tentamos articular essas duas abordagens por meio da seleção e problematização de cinco temas com os quais se depara o professor de História empenhado na realização de atividades com o patrimônio em seu cotidiano docente. Nesse sentido, é nosso objetivo, em primeiro lugar, discutir aspectos das relações entre 
peritos do patrimônio e professores de história, entre as categorias de patrimônio e identidade; patrimônios nacionais e patrimônios da humanidade; virtualidade e fisicalidade do patrimônio e preservação; e criação de memórias no interior das escolas.

Com base nesse temário, e empregando exemplos esparsos colhidos dentro e fora do Brasil, nosso segundo objetivo é indicar cinco questões que, necessariamente, devem ser respondidas pelo professor no momento da criação e/ou da avaliação de planos de trabalho e projetos de intervenção que incorporam a categoria patrimônio como objeto privilegiado de aprendizagem. Cinco questões que ganham a forma de uma ferramenta para o planejamento docente.

O texto, enfim, foi organizado em cinco tópicos, além da conclusão e desta introdução: 1. Entre professores de História e especialistas do patrimônio; 2. Herança e identidade nacional; 3. Fisicalidade e idealidade na seleção do patrimônio nacional; 4. O patrimônio "não existe"; 5. A formalização das metas.

\section{Entre professores de História e especialistas do patrimônio}

Em geral, professores de História e estudiosos do "patrimônio" significam o termo de modo diferente. Professores, com formação historiadora, veem patrimônio predominantemente como fonte histórica, enquanto especialistas (incluindo historiadores da Arte) excedem o seu valor de fonte e o situam como campo do conhecimento, principalmente a Museologia, Arqueologia, Arquivística, Antropologia e a História da Arte. Por esse raciocínio, os estudos sobre patrimônio são subsidiários aos estudos de metodologia do ensino de história, dado que o trabalho do professor de História não se encerra com as tarefas da heurística e da crítica documental, enquanto as atividades dos especialistas em patrimônio não necessariamente avançam até a representação narrativa sobre seus objetos.

Isso não significa dizer que o patrimônio seja empregado exclusivamente como meio, pelo professor de História, e como fim, pelo especialista. Os especialistas em patrimônio colecionável nos museus, por exemplo, se ocupam da preservação de acervos, mas também investem na pesquisa e na educação (HOOPER-GREENHILL, 2004, p. 140). Os que tratam de espécies documentais empenham-se na recolha, preservação, organização de fundos documentais e, ainda, na divulgação (ação cultural) dos seus acervos (BELLOTO, 2010, p. 71; 80). Professores de História, por outro lado, não são contrários à descrição, interpretação, enfim, à historicização de objetos 
tangíveis ou intangíveis com precípua preocupação erudita. Dominantemente, porém, patrimônio (o objeto e o campo) é meio para diferentes fins na docência em História.

Os modos e os critérios de selecionar as coisas dignas do nome "patrimônio", por outro lado, são análogos. Professores de História, por formação, classificam suas fontes sob diferentes perspectivas: (1) materiais e (2) psicológicas (LANGLOIS; SEIGNOBOS, 1898, p. 66-67); (1) intencionais, (2) não intencionais e (3) monumentais (DROYSEN, 1977, p. 400); (1) visuais, orais, escritas e com intenção de memória e (2) monumentos, restos materiais e restos imateriais (BERNHEIM, 1898, p. 157). Idêntica atitude tomam os estudiosos do patrimônio que classificam os seus objetos a partir da fisicalidade ou idealidade dos suportes de informação: objetos de conhecimento cultural (tangível, como uma capela, ou intangível, como um ritual) ou objetos de conhecimento natural (tangível, como uma cachoeira, ou intangível, como determinada música ritual).

Os critérios para valorar o patrimônio, contudo, são diferentes e até divergentes. Professores de História, majoritariamente, selecionam com base nas demandas da questão histórica que os movem no início da pesquisa ou da exposição. A fonte vale pelo que informa sobre o "quem", “onde", "quando", “como" e "por que” ocorreu. Os especialistas em patrimônio, embora possam empregar semelhantes perguntas, são orientados por parâmetros dos seus respectivos saberes e, em geral, avançam em questões mais sofisticadas. $\mathrm{O}$ arquiteto interroga sobre a exemplaridade da técnica construtiva, o arqueólogo destaca a antiguidade do vestígio e analisa a técnica empregada, o crítico de arte se interessa pelo apuro do estilo, o bibliófilo examina a raridade do impresso, o arquivista-conservador trata da composição do suporte-papel e o biólogo analisa a função estratégica uma espécie particular em determinado ecossistema, por exemplos.

Para esses peritos e, também, para professores de História, patrimônios são fontes históricas, embora nem toda fonte histórica sirva como patrimônio. $\mathrm{O}$ ato de elevar uma fonte à categoria de patrimônio depende da aplicação de alguma simbologia ao vestígio. Quando tratados em conjunto, vestígios devem significar bem mais que um agregado de coisas: devem possuir unidade. Isso coloca, novamente, professores de História e peritos do patrimônio em lados diferentes, já que os primeiros nem sempre estão interessados em processos de identização, enquanto os segundos, em geral, imprimem, desde o início dos trabalhos, uma carga semântica dessa natureza aos objetos isolados ou colecionados que estão sob sua responsabilidade. 
Professores de história e especialistas em patrimônio, por outro lado, convergem na descrição da natureza epistêmica dos seus objetos que são, na maioria dos casos, concebidos como coisas em dois sentidos: coisas com existência em si mesmas (essencializadas) ou coisas conscientemente percebidas mediante ideologias ou discursos (inventadas). Aqui, chegamos à nossa primeira proposta de reflexão: como você se coloca diante dessas duas questões? Você se sente mais próximo das demandas, dos interesses e das práticas dos peritos do patrimônio ou do profissional da História? Você entende as coisas do patrimônio como possuidoras de valor intrínseco ou como instituídas por valor extrínseco?

\section{Herança e identidade nacional}

Seja o objeto essencializado, seja o objeto inventado, os profissionais que os reivindicam (embora, mais os professores de História que os peritos) travam algum tipo de luta contra o patrimônio pensado na condição de vestígio do passado a ser consagrado como insumo da identidade nacional. Esse é o significado dominante de patrimônio cultivado há um século e meio, na colonizadora Europa e nos colonizados países americanos.

A relação herança (outro termo para patrimônio) e identidade (nacional) é a mais reivindicada também quando se quer justificar o emprego do patrimônio em atividades do ensino de História, não obstante a variação dos termos empregados por produtores de currículos prescritos e, principalmente, por autores de livros didáticos. ${ }^{3}$ A relação herança-identidade, contudo, pode ser recuada aos tempos pré-modernos, mas apenas para precisarmos a ideia contemporânea de patrimônio. Como veremos adiante, o discurso sobre patrimônio na condição de herança nacional é fenômeno datado do século XIX.

Na baixa Idade Média, segundo Stefan Fisch (2008, p. 2), monarquias, igrejas e oligarquias construíam suas identidades, estabelecendo (inventando) ligações entre a "magnificência", a "glória" e a "missão" e determinados artefatos e acontecimentos. É assim que podemos entender as iniciativas de recuperação, por exemplo, do passado

\footnotetext{
${ }^{3}$ Um breve glossário de patrimônio, inventariado em livros didáticos, nos foi fornecido recentemente por Almir Félix Batista de Oliveira (2016, p. 220): Ações educativas em museus, Alfabetização patrimonial, Arquivos, Centros culturais, Cultura, Cultura imaterial, Cultura material, Educação dos sentidos, Educação para o patrimônio, Educação patrimonial, Folclore, Lugares de memória, Manifestações culturais, Memória, Memória, Memorias, Museu, Patrimônio arqueológico, Patrimônio arquitetônico, Patrimônio cultural, Patrimônio histórico, Patrimônio imaterial, Patrimônio intangível, Patrimônio material, Patrimônio tangível e Tradições.
} 
etrusco e do passado romano, respectivamente promovidas pela Dinastia dos Médici, na Itália, e pelas autoridades eclesiásticas, nos estados papais. É oportuno lembrar que “o primeiro museu público na Europa - O Capitolino (Roma - 1734) - nasceu da fusão das coleções [civis] e das aquisições dos papas” (DONATO, 2014, p. 3).

O mesmo mecanismo podemos perceber no interesse (sobretudo, humanistarenascentista) que levou centenas de antiquários à busca e à descrição de artefatos remanescentes das antiguidades grega e romana (FUNARI; PELEGRINI, sd., pos. 53) nos estados alemães e italianos. Naquele período, algumas pessoas da nobreza ociosa "começaram lentamente a se tornar conscientes de que elas podiam encontrar beleza e emoção de um tipo novo se simplesmente olhassem para sua igreja paroquial ou para o castelo vizinho - assim como poderiam encontrar poesia se eles ouvissem as canções e as histórias dos camponeses" (MOMIGLIANO, 2014, p. 20). Idêntica sensibilidade, mas em operação inversa, estimulou desenhistas e pintores a engajarem-se nos projetos de "conservação dos monumentos de pedra" mediante o registro desse "conhecimento de papel”, na França do século XVIII (HÉRITIER, 2003, p. 32).

Não obstante as iniciativas oligárquicas, clericais e antiquárias pré-modernas, os estudos sobre patrimônio (em sua dimensão coletiva) reservam maior espaço às experiências dos Estados nacionais que legislaram sobre as coisas a serem preservadas sob a justificativa de pertencerem ao conjunto da população natural do país. $\mathrm{O}$ regramento pode ter sido inaugurado durante a Revolução Francesa para preservar os bens confiscados da nobreza e do clero e ameaçados de destruição por parte da população em revolta. O regramento também serviu para conservar e expor os bens pilhados em projetos expansionistas, como os de Napoleão Bonaparte, após submeter extensas regiões e povos do Oriente Médio ao seu controle (LEFEBVRE, 1971, p. 273). Mas a legislação, segundo Pedro Funari e Sandra Pelegrini (s.d, pos. 127-137), foi assentada em diferentes tradições jurídicas, no início do século XIX. Países como França e Brasil, orientados pelo Direito romano (civil), tenderam a ser mais interventores quando estava em jogo o interesse nacional. Países como a Inglaterra e os Estados Unidos, orientados pelo Direito consuetudinário (anglo-saxão), ao contrário, tenderam a limitar as políticas estatais de preservação, quando o bem estivesse sob o regime privado.

Independentemente dessas tradições, a ênfase no patrimônio como instrumento de formação de uma identidade nacional somente foi quebrada após a Segunda Guerra Mundial, com a difusão de algumas ideias-documento, via Organização das Nações 
Unidas (ONU). Duas delas foram: o "patrimônio cultural da humanidade" (1972), com a respectiva valorização da "diversidade" sociocultural no interior de cada sociedade, e a "inclusão dos meios digitais, submetidos às leis de mercado" (2005) (FUNARI; PELEGRINI, sd. pos. 142; 171; 231). A tão criticada Convenção relativa à Proteção do Patrimônio Mundial Cultural e Natural, ainda assentada na primazia do patrimônio edificado e na "ética" preservacionista do século XIX - "conservar como encontrado"-, gerou uma terceira ideia, difundida pela "Convenção para a Salvaguarda do Patrimônio Cultural Imaterial”. Ali, ganhava força a ampliação de diferentes protagonistas (que não o corpo de especialistas) no ato de tipificar o que seria o patrimônio a ser preservado. (SMITH, 2006, p.27-28).

Antes da II Guerra, portanto, a relação entre herança e identidade era dominantemente "nacional", com variações no que diz respeito à (1) natureza do objeto requisitado como bem (histórico-cultural ou natural / material ou imaterial), (2) aos critérios de seleção (valor estético, valor histórico, antiguidade, raridade, valor científico ou valor econômico) e (3) às escalas abrangidas pela herança, com respectivas políticas de proteção (subnacional, nacional, transnacional).

Aqui, alcançamos nosso segundo momento de reflexão. Considerando que o ensino disciplinar de História é, majoritariamente, veículo de construção de identidades, que ideia de identidade você professa para realizar essa finalidade? Pensando nas demandas da sua comunidade, que tipo de coesão é mais urgente, a coesão pautada pela nacionalidade, pelo comunitarismo, por questões de gênero, questões étnicas, profissionais, de credo político ou de credo religioso?

\section{Fisicalidade e idealidade na seleção do patrimônio nacional}

As variações em termos de natureza do objeto, critérios de seleção e escalas abrangidas pela herança refletem modelos de Estado e ideias de nação e nacional. Isso é o que percebemos em olhar de sobrevoo sobre experiências de países como Brasil, França, Argentina e Estados Unidos da América (EUA).

Nos EUA, segundo Peri Arnold (2008), o primeiro objeto de preservação estatal foi o deserto. A natureza era o fator da herança (refletindo o liberalismo econômico de Locke). No século XX, os "lugares históricos" ganharam o mesmo status daqueles lugares naturais nas políticas públicas de preservação. No último quartel do século XIX, os critérios de escolha para a constituição de "parques nacionais" eram as características naturais e, em menor número, os indícios materiais das culturas indígenas e dos 
povoamentos de europeus. Entre os anos 1920 e 1950, os lugares naturais perderam a hegemonia com a preservação de lugares históricos relacionados à Guerra Civil Americana e aos povoamentos de europeus. Entre os anos 1950 e 2010, os critérios foram ampliados para incluir (além dos lugares naturais e de povoação dos migrantes) os lugares de acontecimentos que puseram em crise valores americanos como os direitos civis e a vida de "afro-americanos ilustres".

Contudo, o interesse político-eleitoral e financeiro de congressistas também pôde pesar na instituição de um lugar como suscetível à preservação com financiamento público. Além disso, os especialistas identificaram um movimento de descentralização das políticas de preservação. O surgimento do Parque Nacional de Yellowstone (1872), por exemplo, marca o caráter nacional dessas políticas. Quase um século após, em 1966, os estados são também responsabilizados por essa tarefa. (ARNOLD, 2008, p. 201-202, 209-210).

A herança estadunidense, como vimos, esteve relacionada aos lugares naturais e somente no século $\mathrm{XX}$ foi representada por lugares históricos. Esse foi também o percurso da legislação da Argentina, iniciada com a proteção do Parque Nacional Nahuel (1902). As motivações foram a doação de propriedade por um particular e "a tentativa de coibir o tráfico ilegal de achados arqueológicos valiosos para a Europa e os EUA" (LÓPES, 2008, p. 24). A prática protetiva de "parques nacionais" foi, então, instituída oficialmente em 1902 sob critérios que valorizavam os "monumentos recentes ou contemporâneos", além da "produção artística" e das "paisagens". Em meados do mesmo século, a "escassez e ou antiguidade" e o "valor universal, nacional, regional ou local" foram oficializados como critério, datando desse mesmo período o caráter também provincial e municipal das medidas de proteção (LÓPES, 2008, p. 21-24).

$\mathrm{Na}$ França, os critérios de seleção emergiram, paradoxalmente, da depredação de "títulos, castelos, monumentos e igrejas" que representavam relações sociais de um passado a ser esquecido (o antigo regime), no início da Revolução Francesa: os poderes da Igreja, da realeza e da nobreza. Os critérios de seleção eram, inicialmente, pedagógicos, estéticos e memorialistas (nacionalismo) e os objetos preservados foram os museus, as obras de arte e os palácios nacionais. Na primeira metade do século XIX, foram instituídas as primeiras Comissões e os primeiros corpos de arquitetos "de monumentos históricos". Datam dessa época as iniciativas oficiais de registro e de metodização do trabalho dos conservadores. No último terço do mesmo século, a matéria ganhou um ministério - o das “Belas Artes" (1870) - transformado, adiante, em 
ministério "da Cultura" (1982), "da Cultura e da Francofonia" (1993) e "da cultura e da Comunicação" (1997). A proteção patrimonial foi também ampliada com a criação do “Ministério do Meio Ambiente" (1971) (HÉRITIER, 2003, p. 70-71).

Os títulos dessas e de outras instituições públicas nacionais de preservação indicam as mudanças pelas quais passou a ideia de patrimônio na França: artefatos representativos das belas artes, artefatos da memória nacional e, depois, sítios naturais. As mudanças, por outro lado, reforçam certa "personalização" dos ministros e dos “Arquitetos das Edificações da França” na criação e gestão de políticas de preservação do patrimônio no país. (HÉRITIER, 2003, p. 74-75).

No Brasil, o mando desses corpos técnicos, sobretudo de arquitetos e restauradores, foi quase coetâneo à implantação das primeiras instituições oficiais de preservação, responsáveis pela reunião das "belezas naturais" e dos "monumentos de valor histórico ou artístico". O legislador nacional, como o de outros países, também queria coibir eventual “evasão de obras de artes”. A prescrição estava na Constituição de 1934 (Artigo 10) e a institucionalização dessa ideia se deu com a criação do Serviço do Patrimônio Histórico e Artístico Nacional (SPHAN) e do Museu Nacional de Belas Artes (1937).

Naquele momento, o plano de preservação se estendia aos artefatos, saberes e fazeres eruditos e populares, dada a preocupação do modernista Mário de Andrade com a diversidade cultural do país, ainda fundada nas três conhecidas matrizes étnicas. (OLIVEIRA, 2010, p. 58-59; CORÁ, 2011, pos. 2265). A realização dessa política, contudo, restringia-se à preservação e ao restauro do patrimônio arquitetônico que expressava a memória oficial nacional, a exemplo de edifícios coloniais, barrocos e palácios governamentais neoclássicos e ecléticos (FUNARI; PELEGRINIE, sd., pos. 453). As escolhas estavam ancoradas, em parte, na definição de patrimônio como um "conjunto de bens móveis e imóveis", vinculados a "fatos memoráveis da história do Brasil" por seu "excepcional valor arqueológico ou etnográfico, bibliográfico ou artístico” (CORÁ, 2011, pos. 2304).

Nos anos 1960, sob o estímulo de Paulo Duarte, “jazidas e sítios”, agora, "arqueológicos" ganharam autonomia em relação ao qualificativo "histórico" (FUNARI; PELEGRINI, sd., p. 453). Nas duas décadas seguintes, os critérios de patrimonialização envolveram diretamente o interesse econômico, integrando os governos estaduais no planejamento das ações, com a criação de leis, Institutos e Departamentos especializados, Casas de Cultura, Museus, obras de restauração e de 
implantação da infraestrutura turística de estados como Paraíba, Bahia, Rio de Janeiro e Rio Grande do Sul. A criação da Empresa Brasileira de Turismo (EMBRATUR), integrada aos grandes projetos de "reconstrução de cidades históricas" dos estados de Minas Gerais, Espírito Santo e Rio de janeiro foi efetivada (1973-1979), mas os parâmetros se ampliaram: a própria divisão do Iphan em "patrimônio" e "memória" foi indicador da transformação. Mais importante: vivenciamos a ideia de que preservar era garantir a mudança e, não apenas a permanência. Nesse tempo, sob orientação do designer Aloísio Magalhães, efetivamente, artefatos e instituições relativas às matrizes africanas, como o Terreiro Casa Branca (Ilé Axé Iya Nassô Oká), na Bahia, e o Sítio arqueológico "Quilombo dos Palmares", em Alagoas, foram considerados patrimônio histórico. (OLIVEIRA, 2010, p. 63-64, p. 70-74; FUNARI; PELEGRINI, sd., pos. 489499).

Na Constituição de 1988, a ideia de identidade nacional brasileira foi mantida, mas com ressalvas à "identidade, à ação [e] à memória dos diferentes grupos formadores da sociedade brasileira" (CORÁ, 2011, pos. 2419; 2456). Nas décadas de 2000 e 2010, duas características se destacam nos resultados das políticas públicas para o setor. Por um lado, tivemos a multiplicação de restauros de centros "históricos" ou “zonas portuárias", como ocorreu em Recife, Salvador, Aracaju e Rio de Janeiro, financiados com capital externo e relacionados à indústria do turismo. Por outro, vicejaram as iniciativas de patrimonialização de bens imateriais (FUNARI; PELEGRINI, sd., pos. 514-573).

Temos, ainda, infelizmente, as iniciativas pouco virtuosas de patrimonialização legal para a defesa única e exclusiva de empreendimentos comerciais e eleitoreiros, como a normativa do Senado que transformou os rodeios e vaquejadas em patrimônio cultural brasileiro. (BRASIL, 2017). Por outro lado, temos percebido iniciativas de comunidades que aliam preservação de patrimônio natural e formas de organização social e cultural e econômica, com a criação dos Geoparques. Exemplos, nesse sentido, é o Geoparque Seridó (FREITAS, 2019; MEDEIROS, 2015).

Essas experiências de Brasil, França, Argentina e EUA, nos fornecem um painel da variedade de interesses e das marcas que um modelo de Estado (centralizado ou descentralizado) e de democracia (parlamentar ou presidencialista) e a reatualização das ideias de nação podem implicar nas políticas de seleção e preservação do patrimônio. Observando em duração conjuntural, contudo, é possível identificarmos movimentos semelhantes entre os países citados que alimentam os debates do nosso tempo sobre a 
ideia de patrimônio e reforçam a crítica à tese de que patrimônio é algo a ser conservado por seu valor estratégico à existência e à continuidade da nação: (1) a mudança de ênfase do material ao imaterial; (2) certa abertura do nacional ao universal (da humanidade) e do nacional/universal ao patrimônio de raça, gênero, grupo étnico, comunidade e classe; (3) a crítica à "indústria do turismo"; e (4) a crítica à hegemonia dos especialistas (inclusos os historiadores) na autorização do que deve e não deve ser considerado patrimônio. Esses são, segundo Laurajane Smith (2006, p.35-43), alguns dos principais temas que dominam o debate contemporâneo em escala transnacional.

Um bom modo de nos assenhorarmos de parte desses debates, como inspiradores das nossas atividades docentes no ensino de História, é tentar responder às questões referentes à natureza do patrimônio que queremos objetivamente abordar como mediação para o ensino de História e os modos prováveis de empregá-lo com eficiência: Quais critérios orientam a nossa patrimonialização dos objetos? Onde está o patrimônio manuseável pela nossa Escola?

\section{Patrimônio "não existe"}

Considerando o significado etimológico de patrimônio - bens pertencentes, dados ou herdados (MORAES SILVA, 1813, p. 412) -, o título dessa seção é provocativo. Mas, transmite verdades. A primeira verdade tem base neurofisiológica. Claro que os bens arqueológicos, etnográficos, paisagísticos, históricos, artísticos ou utilitários, os conjuntos urbanos de Alcântara e Paranaguá, as fortificações de São José e dos Reis Magos e os equipamentos da Rede Ferroviária Federal SA., tombados como patrimônio material pelo IPHAN, existem para os seus visitantes. O mesmo podemos dizer sobre a coleção Arqueológica de João Alfredo Rohr (8 mil peças de sambaquis SC), a Pedra do Ingá (PB) e a Serra da Barriga, que abrigou o Quilombo dos Palmares (AL), as celebrações do Círio de Nossa Senhora de Nazaré e do Yaokwa, do povo indígena Enawene Nawe, os lugares como a Cachoeira de Iauaretê, as formas de expressão como o Tambor de Crioula do Maranhão e o Fandango Caiçara e, ainda, determinados saberes, a exemplo do fazer Viola-de-Cocho e do fazer Queijo de Minas. Esses objetos existem e foram tombados ou registrados, respectivamente como patrimônio arqueológico imaterial pelo mesmo Instituto (portal.iphan.gov.br).

Para quem os contempla, edificações, inscrições em pedra e saberes resultam da captura individual de estímulos físicos e químicos, como a luz, o som, a temperatura, a pressão da textura ou o odor, que são levados ao cérebro pelos neurônios e combinados 
pelos sistemas de representação visual, fonológico, gramatical e conceitual (PINKER, 1998, p. 96-102). Os estímulos se transformam em patrimônio, ou seja, ganham realidade, mediante uma combinação que envolve, inclusive, crenças e desejos que, por sua vez, são também possuidores de correspondentes redes neuronais. É esse processamento de informações que nos possibilita afirmar, por exemplo, que a Praça de São Cristóvão (SE) é patrimônio material e a Roda de Capoeira (com o ofício dos mestres de Capoeira) é patrimônio imaterial. A patrimonialização é, em primeira instância, uma operação mental, uma idealização. Os artefatos "praça" e "ofício" são uma espécie nó, cruzamento ou encontro de várias informações inscritas em nossa mente: retângulo + vazio + edifícios $=$ praça; círculo + pessoas + rito + berimbau $=$ Capoeira.

Praça e Capoeira, enfim, são padrões de significação. E o conceito "Patrimônio cultural" é também um padrão de significação, um nó, cruzamento ou encontro de várias informações, tais como: "relevante", "excepcional", "universal", "intacto" e “completo". Assim, quando concentramos a nossa atenção sobre o conjunto sãocristovense, formado pelos edifícios do Palácio Provincial, do Casario Antigo, da Igreja e do Convento de São Francisco, da Capela da Ordem Terceira e da Casa do Folclore Zeca de Noberto e, imperceptivelmente, combinamos estímulos provenientes da memória e da visão, por exemplo, reunindo os dados "relevante", "excepcional", "universal", "intacto", "completo" (http://portal.iphan.gov.br), "Ibérico", "Brasil", "Sergipe" e "nosso", inventamos a Praça de São Francisco como "o" patrimônio cultural da humanidade. ${ }^{4}$

Esse processo nos leva a duas proposições importantes. Em primeiro lugar, o ato de pensar e designar a Praça de São Cristóvão como patrimônio material e o ato de pensar e designar a Capoeira como patrimônio imaterial é a expressão de combinações em dupla direção: do material ao ideal e do ideal ao material. Tais classificações, portanto, é questão de ênfase, onde o material é alvo de simbolização, engendrando o patrimônio tangível, e onde o imaterial está vinculado a determinado suporte físico, engendrando o patrimônio intangível.

\footnotetext{
${ }^{4}$ Como exemplo mais atual desta questão ver, por exemplo, a criação do Memorial das vítimas do COVID-19, em meio digital, objetivando construir uma memória que não seja despessoalizada, centrada somente no número de mortos, mas nominando cada uma das vítimas chamar a atenção para o fato de que, para além da grandiosidade da tragédia, ela tem nomes e histórias: https://inumeraveis.com.br/?fbclid=IwAR1EYJxRZHoV5f8_IJK78sBRo5qlV2qPslf5BmiC_pYKd61GGE1lwpNhzw. Acesso em 17 mai. 2020.
} 
Mas há uma segunda proposição ainda mais importante para o ensino de História. Ao defender e experimentar a Praça de São Cristóvão e a Capoeira como patrimônios, revelamos a corroboração de determinado conjunto de crenças e desejos, interiorizados em nossas mentes por força de um legislador e de alguns meios de difusão, dentre os quais se encontram as aulas dos professores de História.

Aqui entramos em outra verdade da frase-título: "O patrimônio não existe". É evidente que o Vale Vulcânico de Cerco Corá (RN), os Cânions dos Apertados, em Currais Novos (RN) já estavam em construção há milhões de anos, e que as pinturas rupestres do município de Parelhas (RN) estavam constituídas há 9 mil anos. Mas foi necessário um grupo de especialistas, com vasto conhecimento sobre pré-história e com o olhar bastante treinado, por exemplo, para interpretar, desde a década de 1980, pequenos traços inscritos ou pintados na pedra como representações de danças, lutas e sacrifícios rituais e transformar o seu entorno em lugares em patrimônio preservado, espaços de visitação e empreendimentos de geração de emprego e renda.

É evidente (repitamos) que a Praça de São Cristóvão estava lá no platô da colina - de onde se espraiou, no século XVIII, o traçado urbano da quarta cidade mais antiga do Brasil (São Cristóvão) -, bem antes que um grupo de intelectuais iniciasse a campanha por seu tombamento. A mesma coisa dizemos da Capoeira, praticada desde o século XIX, antes que Gilberto Gil, então ministro da Cultura, anunciasse o "Programa Brasileiro e Mundial da Capoeira" (2004) e destacasse a urgência do seu registro como bem cultural, antes até que pesquisadores de história a reconhecessem como reforçadores da autoestima ou um valor a ser apreendido como elemento aglutinador da comunidade (SILVA, 2019, p.252-262). Mas a classificação daquela praça, daquela "dança, luta ou jogo" e daquelas pinturas e cânions como "patrimônio" dependeu de várias operações discursivas, a cargo de um seleto grupo de historiadores da arte, arquitetos, museólogos, antropólogos, arqueólogos, entre outros cientistas e técnicos detentores de grande prestígio social. Eles empregaram seus saberes (e saberes autorizados pelo Estado) para atribuir o significado de "patrimônio" aos dois referidos bens.

É nesse sentido que pesquisadores como Laurejane Smith (2006, p.48-56), afirmam que "patrimônio não existe". Patrimônio é coetâneo (e posterior) ao discurso que o anuncia. Ele é inventado, dito, dado a ver, mediante conjuntos de falas que conformam práticas e de práticas que constroem discursos. Patrimônio não é isoladamente a coisa em sua fisicalidade ou em sua transcendência. Patrimônio é o que 
fazemos com essa coisa. No caso da Praça de São Cristóvão, do Parque Seridó e da Capoeira, o que alguns de nós fazemos é experimentá-los (gosto, cheiro, tato, sons, cantos, alegrias, saudades etc.), lembrá-los (mediante coisas, imagens, pessoas e eventos), produzir novas lembranças e transmitir novas memórias, criando, reforçando e/ou alterando nossas identidades e as identidades dos alunos que com os bens são postos em interação.

Esses usos que fazemos do patrimônio, além dos valores envolvidos em sua seleção, revelam posicionamentos políticos, na medida em que estão (ou não) balizados pelos saberes e práticas dos arquitetos, restauradores e historiadores da arte. Assim, quando planejamos atividades com o patrimônio no ensino de História, situamo-nos, via de regra: (1) "ativa ou passivamente" dentro dos interesses e desejos que relacionam patrimônio à continuidade e à herança nacional; (2) em "oposição ativa e autoconsciente" a esses interesses e desejos, relacionando patrimônio à identidade étnica, de gênero, de classe ou identidade comunitária, isoladamente, concomitantemente ou em camadas; (3) ativa ou passivamente como provedores da relação patrimônio/identidade a partir da monumentalidade e/ou a partir da materialidade e/ou idealidade experimentada comum e cotidianamente pelas pessoas. (SMITH, 2006, p. 48-56).

Em suma e parafraseando Elizabeth Wood e Kiersten Latham (2014, p. 42), quando planejamos atividades com o patrimônio, situamo-nos como titulares de processos de patrimonialização, isto é: selecionadores das coisas tangíveis ou intangíveis para as quais os alunos direcionarão a sua atenção com vistas à ação em processos de identitarização individual e/ou coletiva. Optar por uma dessas proposições significa, em síntese, reconhecer e assumir uma posição ideológica. Você já se questionou sobre essa necessidade? De que maneira você se comporta diante do patrimônio, como contemplador da sua monumentalidade ou como um buscador da experiência da relação que as pessoas comuns mantem com o objeto?

\section{A formalização das metas}

Quem revisita a literatura sobre o tema não tem dificuldades em constatar que as escolhas mais recorrentes na formalização das metas do ensino de História com patrimônio privilegiam finalidades gerais a exemplo de formar a identidade, formar para o exercício da cidadania ou para a convivência democrática. Dependendo do ponto de vista político o professor pode, como anunciamos, engajar-se em projetos conservadores 
ou projetos contestadores. Mesmo que queira, não poderá eximir-se do posicionamento, já político, de induzir os alunos a atribuírem valor a um bem e a excluir outros bens. Em quaisquer dessas posições, o professor também poderá planejar as habilidades relacionadas ao conhecer e preservar o bem ou a memória evocada pelo bem ou planejar habilidades relacionadas à experimentação, à revelação e/ou à criação de memórias.

Algumas iniciativas de planejamento costumam encerrar-se por aí (conhecer / preservar ou experimentar / criar) e, infelizmente, sem definir a identidade, a cidadania ou a democracia com a qual se está a tratar. Outras hierarquizam ainda mais os conhecimentos e habilidades, optando por focar em capacidades gerais ou transversais de educação humana ou descer às capacidades disciplinares (da História, da Geografia etc.).

Quem toma a segunda orientação, formula as suas atividades dentro de uma ideia de aprendizagem histórica, a exemplo de desenvolver o pensamento histórico, desenvolver a competência narrativa ou o desenvolver o pensamento crítico. Em geral, chega ao detalhe de selecionar as habilidades relativas às referidas à essas ideias de aprendizagem, destacando, por exemplo, os procedimentos de investigação (habilidades de problematização, busca, crítica e interpretação de fontes) e de escrita da História (habilidades de argumentação, generalização e composição).

$\mathrm{Na}$ cidade de Jaén (Espanha), uma iniciativa de formação inicial de professores transformou os vestígios da Guerra Civil (um cemitério, uma fachada de Igreja com marcas de bombardeio, um abrigo antiaéreo, entre outros) em "patrimônio" por testemunharem sobre o ódio, a intolerância e o autoritarismo. Os objetivos eram dominantemente cultivar valores contemporâneos (opostos aos que resultaram nas perseguições da Guerra Civil Espanhola), como a igualdade, a tolerância, as práticas de cidadania, os direitos humanos e a manutenção do sistema político-democrático. Todos esses valores estavam em sintonia com o currículo nacional para o professorado (competências sociais e de cidadania) e para o componente curricular "ciências sociais" (a Guerra Civil). A habilidade-síntese, comum a várias disciplinas, poderia ser mencionada como a "criação do pensamento crítico" nos jovens universitários. (MILLA, 2016, p. 264). A execução do experimento consistiu no emprego de dois itinerários de visita orientados por meios de ensino diferentes: formal (exposição docente) e informal (aprendizagem vivenciada nos cenários de guerra). A conclusão do professor Santiago Jaén Milla, coordenador da atividade, foi a de que os alunos tiraram 
maior proveito da segunda alternativa, também planejada a partir das seguintes metas de aprendizagem:
a) conhecer lugares de memória na cidade de Jaén;
b) criar vínculos emocionais com a cidade a partir de espaços patrimoniais;
c) refletir sobre a perda do valor da vida, decorrente de um conflito armado;
d) formar cidadãos e cidadãs comprometidos com a defesa dos princípios e valores democráticos e com a resolução pacífica de conflitos;
e) refletir sobre o tratamento desigual que as vítimas da Guerra Civil têm recebido. (MILLA, 2016, p. 254).

Se as expectativas de aprendizagem acima foram estabelecidas para os usos do patrimônio de Guerra na atividade formal e na atividade informal, como ocorre em algumas das nossas iniciativas, podemos concluir que as metas, isoladamente, não são qualificadores de um projeto. Em geral, conjuntos de conhecimentos, habilidades e capacidades são empregados de modo combinado e não ortodoxo. A construção de identidades, a formação para a cidadania e o convívio democrático se adequam como metas à maioria dos planejamentos e as habilidades de investigação fazem parte de planos mais ou menos conservadores em relação ao patrimônio nacional. As misturas também são feitas ao sabor dos vários condicionantes das prescrições curriculares estatais, das prescrições de formação profissional em termos de Didática da História e até mesmo das tradições dominantes de formação de professores de História em cada país

O Manual Aqueduct - Acquiring key competences trhrough heritage education (2013) é um exemplo de formatação dos objetivos das atividades com patrimônio a partir de prescrições curriculares para a escola. Ele foi construído para empregar elementos do patrimônio natural e cultural no desenvolvimento das competências chave estabelecidas no European Reference Framework (ERF) e orientado por documentos referenciais da UNESCO. Deste último dispositivo, seus coordenadores incluíram a ideia de que o patrimônio material e o imaterial são simultaneamente conhecimentos para a "aprendizagem" e "contexto" para a aprendizagem. Do ERF, o Aqueduct conservou os fins do emprego escolar do patrimônio, atrelando-os ao desenvolvimento de "competências-chave transversais" (competências não disciplinares) acordadas para os países da Comunidade Europeia: "aprender a aprender, competências sociais e cívicas, empreendedorismo e consciência e expressão cultural" (GUSSEN; VAN LAKERVELD; Van Lakerveld, 2013, p. 9). 
Como resultado dessas escolhas, as sequências didáticas dos vários projetos indicados pelo Aqueduct (visitas a museus de história local, construção de museus pessoais, exploração da escola como patrimônio etc.) combinam duas ou mais capacidades e misturam abordagens de distinta proveniência pedagógica (GUSSEN et. al, 2013, p. 22-23). Assim, as atividades planejadas para o desenvolvimento de determinada ação em certo contexto, sob qualidade específica (desenvolvimento de capacidade) podem combinar a aprendizagem por exposição com a aprendizagem por descoberta e aprendizagem cooperada, a exemplo da atividade que envolve alunos de 8 anos, em quatro aulas, no interior de uma sala de aula, um museu ou em experimentação em determinado sítio arqueológico.

Quadro 1: Plano de atividades do Aqueduct

Título da atividade - "Quando o homem ainda era criança"

Objetivo - Explorar a noção de pré-história e evolução humana

Competências-chave - Aprender a aprender e expressão/consciência cultural

\begin{tabular}{|l|l|l|}
\hline $\begin{array}{l}\text { Habilidades, conhecimentos e } \\
\text { valores/Atividades }\end{array}$ & Local Aprendizagens \\
\hline $\begin{array}{l}\text { 1. Conhecer as funções e tarefas do } \\
\text { profissional arqueólogo }\end{array}$ & Sala de aula & Por exposição \\
\hline $\begin{array}{l}\text { 2. Conhecer achados arqueológicos mediante } \\
\text { exposição no museu de Pré-História }\end{array}$ & $\begin{array}{l}\text { Museu de Pré- } \\
\text { História }\end{array}$ & Por exposição \\
\hline $\begin{array}{l}\text { 2. Relatar e discutir impressões da visita ao } \\
\text { museu de Pré-História }\end{array}$ & Sala de aula & Cooperada \\
\hline $\begin{array}{l}\text { 4. Aplicar técnicas ornamentais e utilitárias } \\
\text { paleolíticas }\end{array}$ & $\begin{array}{l}\text { Museu de Pré- } \\
\text { História }\end{array}$ & Por descoberta \\
\hline $\begin{array}{l}\text { 5. Investigar estrutura e função de cabanas da } \\
\text { Idade do Bronze }\end{array}$ & $\begin{array}{l}\text { Parque temático em } \\
\text { sítio arqueológico }\end{array}$ & Por descoberta \\
\hline 6. Aplicar técnicas de escavação & Sítio arqueológico & Por descoberta \\
\hline $\begin{array}{l}\text { 7. Relatar visita e examinar peças colhidas } \\
\text { durante a escavação arqueológica }\end{array}$ & Sala de aula & Cooperada \\
\hline $\begin{array}{l}\text { 8. Narrar por desenhos todas as etapas das } \\
\text { atividades e apresentá-las aos pais }\end{array}$ & Sala de aula & Cooperada \\
\hline
\end{tabular}

Fonte: Gussen et. al [2013], p. 44-45. Adaptado.

Em Portugal, Elena Pinto - mestre em Patrimônio e Turismo doutoranda em Educação, com foco na Educação Histórica - sugere que os professores portugueses planejem atividades que ponham os alunos em contato com os artefatos, ao ar livre e em ambiente lúdico, possibilitando a efetivação de uma "aprendizagem significativa", o “desenvolvimento do pensamento histórico e social" e a aquisição das competências de 
“compreensão-contextualização" (PINTO, 2009, p. 279; 298). Aí estão congregadas algumas metas disponibilizadas por teorias da Educação (Pedagogia Ativa) e por teóricos da História (Jörn Rüsen).

$\mathrm{Na}$ Inglaterra e nos EUA (e em vários outros países), propostas com o patrimônio para o ensino de História refletem características nacionais de formação em História. Pelo estudo de Pedro Miralles (2017, p. 278-280), somos informados de que as metas dos futuros professores de História desses países diferem bastante, mesmo quando adotam pedagogias ativas (frente às pedagogias memorísticas). Espanhóis, dominantemente, atribuem alta pontuação ao "patrimônio como recurso didático na aula de História e como estratégia metodológica ou técnica de avaliação.” Já os ingleses preferem atribuir maior valor ao patrimônio como elemento para a "busca e seleção de fontes e a resolução de problemas históricos" (explicação e argumentação).

Essa última é também a característica dominante dos trabalhos brasileiros, produzidos no âmbito do Mestrado Profissional em Ensino de História (PROFHISTÓRIA). Na cidade de Natal, a professora Olga Suely Teixeira (2018, p. 11; 64-72) empenhou-se na produção de um museu portátil que possibilitasse a efetivação de aprendizagens históricas significativas entre os alunos dos anos iniciais, do Colégio Essencial. Com a meta de "transformar as experiências pessoais" de alunos em instrumentos de descoberta histórica, Teixeira construiu artefatos e os acondicionou em um baú. Com esses objetos, tentava auxiliar ao desenvolvimento de habilidades típicas do historiador, como investigar, interpretar e narrar, partindo da experiência dos alunos com o seu próprio lugar de moradia.

No mesmo ano, Josirene de Lucena (2018, p. 15; 66-67) se interessava por "vivências", "saberes" e os "fazeres" dos pescadores e das pescadoras da cidade de Itapissuma (PE), considerados entre os "maiores patrimônios culturais da cidade" (LUCENA, 2018, p. 15). Ela pôs os alunos a "investigar" (coleta de depoimento oral) e a editar informações em uma "cartilha". Em termos de objetivos cognitivos, desejava desenvolver "empatia e sensibilidade" dos alunos em relação às questões sociais do seu meio. A cartilha registrava os saberes e os significados da pesca para os protagonistas, como também alguns acontecimentos marcantes em suas vidas, relacionáveis à aprendizagem histórica como fatores formativos da "consciência histórica" dos alunos.

Esses exemplos de planejamento das metas, traduzíveis em expectativas de aprendizagens, atividades e até itens de prova, como vemos, nos induzem lhes provocar com mais um grupo de questões: seu plano de aula, de unidade ou de curso está 
centrado em habilidades, conhecimentos e capacidades gerais/universais? Seu plano está centrado em habilidades, conhecimentos e capacidades que traduzem uma ideia de aprendizagem histórica disciplinar? Seu plano oscila ou mistura essas duas possibilidades de formalização das metas?

\section{Considerações finais}

Iniciamos este artigo com a meta de articular as histórias do pensamento e da prática de preservação com a oferta de meios para o emprego do patrimônio no ensino História. Discutimos diferentes pares de assuntos antitéticos envolvidos na implantação de propostas pedagógicas. Associamos os termos patrimônio e ensino de História com o fito de oferecer alternativas conceituais e sugestões de atividades para o planejamento das aulas de História destinadas aos alunos da educação básica. Com ele, quisemos afirmar que há distinções e similaridades entre o trabalho do professor de História e dos demais profissionais que atuam com a investigação e difusão do patrimônio e, mais importante, que os primeiros não necessariamente devem importar de modo integral as alternativas de manuseio do patrimônio produzidas pelos segundos. A atitude aconselhada é, como sempre, o diálogo interdisciplinar, determinado pelas finalidades pensadas para o componente curricular História.

Ao longo dos cinco tópicos, apresentamos informações e, ainda, algumas questões que supomos poderem configurar um roteiro de orientação para o planejamento e a avaliação de ações que envolvam a categoria patrimônio. Esse roteiro pode ser aplicado, inclusive, sistematicamente, como um formulário, como podemos acompanhar agora.

Em primeiro lugar, percebemos que planejar e implementar medidas do gênero implica na percepção de patrimônio como discurso e prática construídos também pelo professor de História que deve, em primeiro lugar, expressar sua posição política em relação à invenção desse patrimônio em seus vínculos com a formação de identidades: Estou a tratar de patrimônio nacional, patrimônio local ou patrimônio nacional-local? Estou a inventar ou reforçar patrimônios de classe, etnia ou gênero ou patrimônios de modo interseccional? Estou a formar indivíduos, cidadãos ou indivíduos-cidadãos?

As respostas a tais questionamentos não raro levarão ao professor refletir e explicitar também sua posição mediante a escolha de capacidades diretamente relacionadas às metas que conformarão as atividades junto os alunos: quais verbos melhor as expressam, conhecer e preservar ou contrapor, reinventar e experimentar o 
DOI: 10.47694/issn.2674-7758.v2.i5.2020.175197

patrimônio? Quais atitudes darão o tom da proposta de ensino, a atividade, a passividade, a mescla de atividade e passividade ou a indiferença diante de objetos?

Vencidas as etapas de identificação das proposições políticas, chegamos, enfim ao nível operacional, onde as ideias de aprendizagem e aprendizagem histórica devem ser combinadas com as prescrições de currículos nacionais, locais ou escolares.

Nesse sentido, a variação de resultados é imensa. Como afirmamos, um entusiasta da alfabetização histórica de Peter Lee ou da consciência histórica de Jörn Rüsen, com suas respectivas ênfases na combinação de conteúdo metahistórico e conteúdo substantivo e o desenvolvimento de habilidades construtoras da competência narrativa, pode muito bem fazer valer as suas ideias de metas e de campo da Didática da História ou de metas e campo da Didática Geral. O que se espera, enfim, é que o professor de História esquematize as metas de uso dos objetos com clareza e convicção sobre significado dos conceitos e a coerência entre os conceitos que são instrumentos de produção de sentido.

Ao propor que os alunos experimentem os objetos para reforçar ou questionar determinada configuração identitária, enfim, é importante que ele saiba traduzir em habilidades o que designou por "experiência" e em valores o que designou por "identidade". Somente dessa maneira o professor poderá avaliar o potencial transformador de comportamentos e valores que a relação patrimônio e ensino de História poderá proporcionar.

\section{Referências:}

ARNOLD, Peri E. American Heritage and the Development of Historic Preservation Policy in the United States. In: FISCH, Stefan (org.). National Approaches to the Governance of Historical Heritage over Time. A Comparative Report. Amsterdam: IOS Press, 2008.

BELLOTTO, Heloísa Liberalli. A função social dos arquivos e o patrimônio documental. In: PINHEIRO, Áurea da Paz; PELEGRINI, Sandra C. A. Tempo, memória e patrimônio cultural. Terezina: Anpuh-PI, 2010. p. 73-85.

BERNHEIM, Ernst. Lehrbuch der historischen Methode. Leipzig: Duncker \& Humblot, 1889.

BITTENCOURT, Circe Maria Fernandes. Estudo do meio como prática interdisciplinar. In: Ensino de História: fundamentos e métodos. São Paulo: Cortez, 2004. p. 273-290. 
BRASIL. Senado Federal. Vaquejada se tornou patrimônio por lei. Em discussão. Brasília, n. 31, abr. 2017. Disponível em< https://www12.senado.leg.br/emdiscussao/edicoes/vaquejada/vaquejada/vaquejada-setornou-patrimonio-por-lei >. Acesso em: 12 nov. 2019.

CORÁ, Maria Amélia Jundurian. Do material ao imaterial: patrimônios culturais do Brasil. São Paulo: FAPESP, 2011.

DONATO, Maria Pia. Il patrimonio e le sfide di ua storia interconnessa. A proposito del livro di T. Montanari - Istruzioni per l'uso del futuro. Il patrimonio culturale e la democrazia che verrà. Giornale di storia, v. 14, p.1-8, 2014. Disponível em< www.giornaledistoria.net >. Acesso em: 23 nov. 2019.

DROYSEN, Johan Gustav. Historik. Band 1: Rekonstruktion der ersten vollständigen Fassung der Vorlesungen (1857). Grundriss der Historik in der ersten handschriftlichen (1857/1858) und in der letzten gedruckten Fassung (1882). Stuttgart: FrommannHolzboog, 1977.

FISCH, Stefan. National Approaches to the Administration of Historical Heritage A Comparative Report. In: FISCH, Stefan (org.). National Approaches to the Governance of Historical Heritage over Time. A Comparative Report. Amsterdam: IOS Press, 2008. p. 1-13.

FREITAS, Idiamara Nascimento de. Projeto Geoparque Seridó: um estudo das práticas turísticas como propulsor para o desenvolvimento local. Dissertação de Mestrado (Programa de Pós-Graduação em Turismo - PPGTUR), 2019.

FUNARI, Pedro Paulo; PELEGRINI, Sandra de Cássia Araújo. Patrimônio histórico e cultural. Rio de Janeiro: Zahar, sd.

GUSSEN, Ingrid; VAN LAKERVELD, Jaap (ed.) Aqueduct - Acquiring kei competences through heritage education. Bilzen: Alden Biesen, [2013].

HÉRITIER, Annie. Genèse de la notion de patrimoine culturel (1750-1816). Paris: L'Harmattan, 2003.

HOOPER-GREENHILL, Eilean. Museums: ideal learning environments. In: Museums and their visitors. London: Routledge, 2004. p. 140-170.

HORTA, Maria de Lourdes Parreiras; GRUNGERG, Evelina; MONTEIRO, Adriane Queiroz. Guia básico da educação patrimonial. Rio de Janeiro: Museu Imperial, [1999].

IPHAN. Monumentos e espaços públicos tombados - São Cristóvão (SE) - Praça São Francisco. Disponível em: <http://portal.iphan.gov.br/pagina/detalhes/1462/>. Acesso em: 20 nov. 2019. 
IPHAN. Parecer .0313/08/2006 - Registro da Capoeira como Patrimônio Cultural do Brasil. Salvador: IPHAN; $7^{\text {a }}$ Superintendência Regional, 2006. Disponível em: http://portal.iphan.gov.br/uploads/ckfinder/arquivos/parecer\%20oficio\%20mestre\%20ca poeira.pdf >. Acesso em: 20 nov. 2019.

LANGLOIS, Charles-Victor; SEIGNOBOS, Charles. Introduction aux études historiques. Paris: Kimé, 1992.

LEFEBVRE, Georges. La naissance de l'historiographie moderne. Paris: Flammarion, 1971.

LÓPES, Julio Oscar. L'Argentine, un cas particulier em Amérique Latine. Un pays riche en histoire et contrastes. In: FISCH, Stefan (org.). National Approaches to the Governance of Historical Heritage over Time. A Comparative Report. Amsterdam: IOS Press, 2008.p.17-30.

LUCENA, Josirene Souza Inocêncio de. História de pescadores e pescadoras da Pedra Negra: uma proposta de educação patrimonial aplicada no ensino de História. Dissertação (Mestrado em Ensino de História) - Programa de Pós-Graduação em Ensino de História, Universidade Federal de Pernambuco, Recife, 2018

MEDEIROS, Janaina Luciana de. Práticas Turísticas em geosítios: uma avaliação ambiental no Projeto Geoparque Seridó- RN. Dissertação de Mestrado (Programa de Pós-Graduação em Turismo - PPGTUR), 2015.

MILLA, Santiago Jaén. Testigos de la infamia. Itinerarios por el patrimonio de la Guerra Civil en Jaén. In: MOLINA PUCHE, Sebastián; ESCRIBANO-MIRALLES, Ainoa; DÍAZ-SERRANO, José (ed.). Patrimonio, identidad y ciudadanía en la enseñanza de las ciencias sociales. Murcia: Universidad de Murcia, 2016. p. 252-265.

MIRALLES, Pedro Martínes et. al. Patrimonio, competencias históricas y metodologías activas de aprendizage. Um análisis de las opiniones de los docentes en formación en España e Inglaterra. Estudios Peagógicos, v. 43, n. 4, p. 161-184, 2017.

MOMIGLIANO, Arnaldo. História antiga e o antiquário. Anos 90, Porto Alegre, v. 21, n. 39, p. 19-76, jul. 2014.

MORAES SILVA, Antonio de. Diccionario da Lingua Portugueza. 2ed. Lisboa: Typographia Lacerdina, 1813. T.2.

OLIVEIRA, Almir Félix Batista. Patrimônio histórico: preservar é preciso... In: Memória, História e Patrimônio histórico: políticas públicas e a preservação do patrimônio histórico. São Cristóvão: Editora da UFS, 2010. p. 47-74.

O patrimônio cultural e os livros didáticos de História ou de como se constrói o sentimento de pertencimento (Brasil, 200-2005). Tese (Doutorado em História) Programa de Pós-Graduação em História Social, Pontifícia Universidade Católica de São Paulo, 2016. 
PACHECO, Ricardo de Aguiar. Ensino de História e Patrimônio Cultural: um percurso docente. Jundiaí: Paco, 2018.

PELEGRINI, Sandra de Cássia Araújo. Ensino de História e educação patrimonial no Brasil. In: ROLEDO, Maria Aparecida Leopoldino Tursi (org.). Ensino de História: ensaios sobre questões teóricas e práticas. Maringá: Editora da Universidade Estadual de Maringá, 2011. p.73-97.

PINKER, Steven. Como a mente funciona. Companhia das Letras, SP, 1998.

PINTO, Helena. O triângulo patrimônio-museu-escoa: que relação com a Educação Histórica? In: CERCADILHO, Lis; SCHMIDT, Maria Auxiliadora; BARCA, Isabel. Aprender História: perspectivas da Educação Histórica. Ijuí: Editora Unijuí, 2009. p. 271-302.

RAMOS, Francisco Régis Lopes. A danação do objeto: o museu no ensino de História. Chapecó: Argos, 2004.

SILVA, Jefferson Pereira da. Ensino para as relações étnico-raciais e a formação do cidadão: o valor da capoeira. In: Denise Pereira. (Org.). Campos de Saberes da História da Educação no Brasil 2. Ponta Grossa/PR: Atena Editora, 2019, p. 352-362.

SMITH, Laurajane. The uses of heritage. London: Routledge, 2006.

TEIXEIRA, Olga Suely. A História Local como um caminho para o ensino significativo de História nos anos iniciais, UFRN/Profhistória, 2018.

WOOD, Elizabeth; LATHAM, Kiersten. The objects of experience: transforming visitor-object encounters in Museums. Ealnut Creec: Left Coast Press, 2014.

ZARBATO, Jaqueline Aparecida Martins. Cultura, memória e patrimônio na sala de aula: o uso do monumento na aprendizagem histórica. In: Patrimônio, cultura $e$ processos educativos em História: percursos e reflexões. Campo Grande: Life, 2018. p. 43-56.

Artigo recebido em 20 de junho de 2020. Aprovado em 03 de agosto de 2020. 